\title{
Rapid evolution of prezygotic barriers in non-territorial damselflies
}

\author{
ROSA ANA SÁNCHEZ-GUILLÉN ${ }^{1,2,3 *}$, ALEX CÓRDOBA-AGUILAR ${ }^{2}$, \\ ADOLFO CORDERO-RIVERA ${ }^{3}$ and MAREN WELLENREUTHER ${ }^{4}$ \\ ${ }^{1}$ Institut de Biotecnologia i Biomedicina, Universitat Autònoma de Barcelona, Campus UAB, 08193, \\ Cerdanyola del Vallès, Barcelona, Spain \\ ${ }^{2}$ Departamento de Ecoloxía e Bioloxía Animal, Universidade de Vigo, Vigo 36002, Spain \\ ${ }^{3}$ Departamento de Ecología Evolutiva, Instituto de Ecología, Universidad Nacional Autónoma de \\ México (UNAM), Mexico D.F. 04510, Mexico \\ ${ }^{4}$ Department of Biology, Lund University, Ecology Building, Lund SE-223 62, Sweden
}

Received 15 March 2014; revised 2 May 2014; accepted for publication 3 May 2014

\begin{abstract}
A central question in evolutionary biology concerns the accumulation of reproductive barriers during speciation. However, separating the reproductive barriers that have led to speciation from those that have secondarily accumulated (i.e. after initial divergence) is a widely recognized problem. Ideal candidate species for overcoming this problem are young species, where time for additional barriers to accrue has been limited. In the present study, we add to previous studies investigating the strength of reproductive barriers between the parapatric damselflies Ischnura elegans and Ischnura graellsii by quantifying seven prezygotic barriers between the allopatric pairs of I. elegans and Ischnura genei, as well as I. graellsii and I. genei. Specifically, we measured four premating (temporal, sexual, mechanical ${ }_{\text {I }}$, and mechanical ${ }_{\text {II }}$ ) and three postmating (oviposition success, fecundity, and fertility) barriers using experimental approaches and, for first time, we investigated the mechanisms causing mechanical isolation, which is the strongest reproductive barrier in ischnurans. The findings of the present study support the notion that premating barriers are generally strong and contribute significantly to total reproductive isolation in young lineages (65-98\%), although they never solely lead to complete isolation. Asymmetry was generally stronger in premating than in postmating barriers, and was driven mostly through asymmetry in mechanical isolation, which is caused by morphological divergence of secondary sexual appendages. We found that barriers act multiplicatively in all species combinations tested, with the exception of sexual isolation, which was not detected. Our results are consistent with a recent allopatric speciation scenario driven by differences in male anal appendages, either impeding copulation or affecting female preferences. Taken together, the results from this and previous studies in diverse odonate genera suggest that premating barriers have evolved rapidly in ischnuran damselflies and, although reproductive isolation in ischnurans is more commonly the result of several barriers acting together, morphological divergence of secondary sexual appendages appears to be a common factor facilitating premating isolation in this group. (c) 2014 The Linnean Society of London, Biological Journal of the

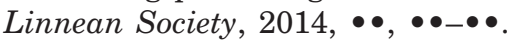

ADDITIONAL KEYWORDS: asymmetric reproductive isolation - odonata - prezygotic isolation - speciation.

\section{INTRODUCTION}

The accumulation of reproductive barriers during speciation has been a central question in evolutionary biology. Some reproductive barriers may evolve to

*Corresponding author. E-mail: rguillenuvigo@hotmail.com completion before others, such that a single reproductive barrier contributes disproportionately to the initial species' boundary (Mendelson, 2003; Coyne \& Orr, 2004). More commonly, however, several reproductive barriers act together to prevent genetic exchange between lineages (Dopman, Robbins \& Seaman, 2010; Sánchez-Guillén, Wellenreuther \& Cordero-Rivera, 2012) and the relative importance of 
these barriers varies widely among groups. Knowledge about the order in which reproductive barriers accumulate allows the identification of which isolating mechanisms contribute disproportionally to the cessation of gene flow in a given lineage at the initial start of divergence. Identification of the first barriers that promote lineage divergence requires the study of young lineages to minimize the effect of additional barriers that evolve with increasing lineage divergence (Mendelson, Imhoff \& Venditi, 2007).

Reproductive barriers are typically categorized depending on whether they take place before (premating) or after mating (postmating) and before (prezygotic) or after zygote formation (postzygotic) (Dobzhansky, 1937). Premating barriers take place before mating, whereas postmating prezygotic barriers act after mating or gametic contact and reduce the probability of successful fertilization. Postzygotic barriers act by reducing the fitness of hybrids and therefore the probability of genetic introgression (Dobzhansky, 1937). Frequently, the strength with which these reproductive barriers prevent hybrid formation differs between reciprocal crosses, a phenomenon termed asymmetric isolation. This asymmetry is common across a wide range of taxa (Coyne \& Orr, 2004), including invertebrates (Coyne \& Orr, 1989; Presgraves, 2002; Sánchez-Guillén et al., 2012), vertebrates (Mendelson, 2003), and plants (Turelli \& Moyle, 2007; Lowry et al., 2008). Examples of animals showing asymmetry in prezygotic barriers include fruit flies (Kaneshiro, 1980), salamanders (Arnold, Verrel \& Tilley, 1996), snakes (Shine et al., 2002), and damselflies (Sánchez-Guillén et al., 2012), although these studies have mainly focused on sexual isolation (Kaneshiro, 1980). By contrast, studies investigating asymmetry in postzygotic barriers have predominantly focused on reinforcement (Yukilevich, 2011), Darwin's corollary (Turelli \& Moyle, 2007), and Haldane's rule (Haldane, 1922) in plants (Turelli \& Moyle, 2007) and fishes (Bolnick et al., 2008; Polačik \& Reichard, 2011). Asymmetry in prezygotic isolation (sexual isolation) is predicted to be a transient stage characteristic of intermediate stages of divergence (Arnold et al., 1996) or an outcome of reinforcement (Yukilevich, 2011), whereas asymmetry in postmating isolation requires genetic interactions involving genes to be asymmetrically transmitted (Turelli \& Moyle, 2007).

The damselfly genus Ischnura is one of the most diverse genera of the family Coenagrionidae (Odonata), including approximately 70 species (Dumont, 2013). This genus consists of nonterritorial damselflies where males compete for mates in a scramble fashion (Cordero-Rivera, 2000). This genus represents an ideal model system to explore the accumulation of reproductive barriers during different stages of lineage divergence because of many of the species are very young (Sánchez-Guillén, Córdoba Aguilar, Cordero Rivera \& Wellenreuther, 2014), can easily be observed in the field, and are suitable for laboratory experimental manipulation of reproductive behaviours. In previous studies, we have investigated the mechanisms leading to reproductive isolation between the sister parapatric species pair Ischnura elegans and Ischnura graellsii by measuring 19 preand postzygotic barriers (Monetti, Sánchez-Guillén \& Cordero Rivera, 2002; Sánchez-Guillén, Van Gossum \& Cordero-Rivera, 2005; Sánchez-Guillén et al., 2012; Sánchez-Guillén, Córdoba-Aguilar \& Cordero-Rivera, 2013a) and investigated whether reproductive isolation is correlated with genetic divergence in this and other damselfly genera (Sánchez-Guillén et al., 2014). In these studies, we found that isolation is highly asymmetric and that mechanical isolation is the strongest component of isolation, and also detected a positive relationship between genetic divergence and the degree of reproductive isolation between taxa. In the present study, and unlike previous work, we investigated whether these previous findings hold when more species combinations are tested by quantifying the barriers causative of reproductive isolation between I. elegans and Ischnura genei and I. graellsii and I. genei. Furthermore, we are also investigating for the first time the mechanisms behind the strong mechanical isolation between ischnuran species by conducting a morphological analysis of the secondary genitalic structures and body size. We compare the strength of reproductive barriers in I. elegans, I. genei, and I graellsii, which are all in the early stages of species divergence (the percentage of genetic divergence for cytochrome oxidase II is 0.31 between I. elegans and I. genei, and 0.09 between I. genei and I. graellsii) (Carchini, Cobolli, De Matthaeis \& Utzeri, 1994; Sánchez-Guillén et al., 2014), making them suitable candidates for the investigation of reproductive barriers causative in the cessation of gene flow. All three species occur in the Mediterranean basin, although their distributions are almost completely allopatric (Fig. 1). Ischnura elegans is the most widespread European damselfly, which extends from Ireland to Asia, whereas I. graellsii and I. genei are endemic species of Iberia and North Africa, and the Tyrrhenian Islands, respectively (Boudot et al., 2009). In Spain, I. elegans and I. graellsii overlap at their distribution boundaries, forming a sympatric region where they hybridize and, consequently, genes of I. graellsii are introgressed into the I. elegans gene pool (Sánchez-Guillén et al., 2011). Ischnura genei and I. elegans are allopatric but eventually come into contact and also show a pattern of introgressive hybridization of $I$. genei genes into the I. elegans gene pool (Sánchez-Guillén et al., 2014). Finally, I. graellsii 


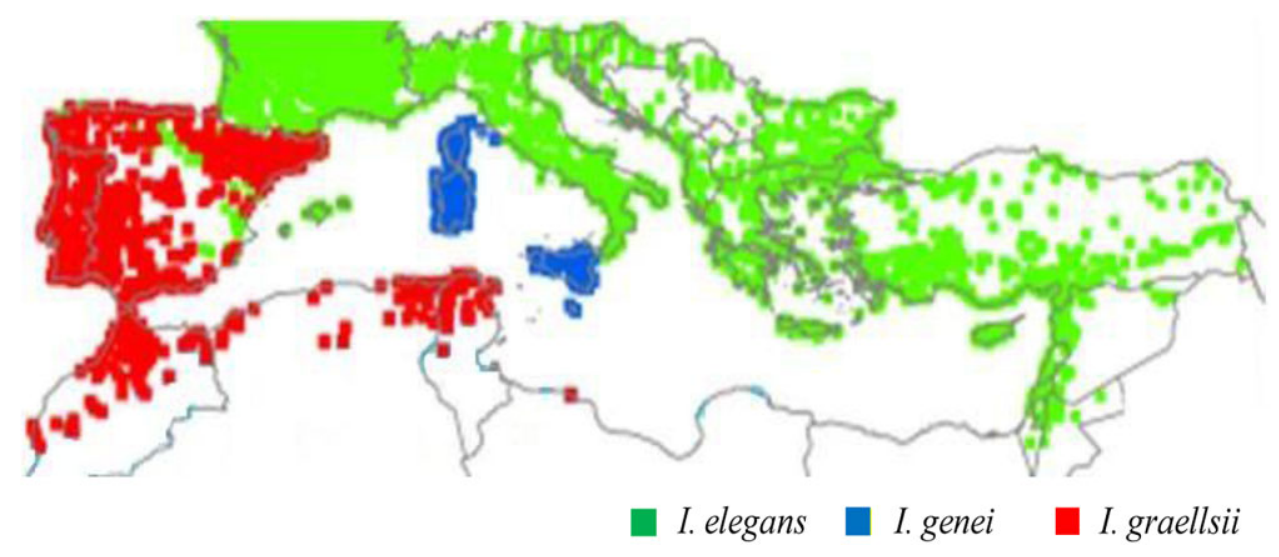

Figure 1. Mediterranean distribution of the three studied species: Ischnura elegans, Ischnura genei, and Ischnura graellsii.

and I. genei are completely allopatric. Moreover, all combinations of these three species can be induced to hybridize in the laboratory. Together, the aforementioned characteristics make these damselflies ideal model species to (1) identify initial reproductive barriers; (2) understand which barriers evolve most rapidly; and (3) identify possible asymmetry in barriers. We examined these aspects by quantifying the strength of seven prezygotic barriers (acting before fertilization) in the form of four premating (temporal, sexual, and two forms of mechanical) and three postmating (oviposition success, fecundity, and fertility) barriers, between I. genei and I. elegans, as well as betweem $I$. genei and $I$. graellsii, in both reciprocal cross directions using experimental approaches in the laboratory.

\section{MATERIAL AND METHODS \\ LABORATORY REARING}

Last-instar larvae of approximately 200 I. elegans $\left(42^{\circ} 45^{\prime} 29.64^{\prime \prime} \mathrm{N}, 9^{\circ} 5^{\prime} 39.84^{\prime \prime} \mathrm{W}\right)$ and 200 I. graellsii $\left(42^{\circ} 27^{\prime} 12.41^{\prime \prime} \mathrm{N}, 8^{\circ} 50^{\prime} 54.88^{\prime \prime} \mathrm{W}\right)$ individuals, both from allopatric Spanish populations, were sampled in August 2009. Additionally, eggs (approximately 1000) of 22 I. genei females $\left(37^{\circ} 51^{\prime} .54^{\prime \prime} \mathrm{N}, 13^{\circ} 14^{\prime} .38^{\prime \prime}\right.$ and $\left.37^{\circ} 01^{\prime} .31^{\prime \prime} \mathrm{N}, 14^{\circ} 20^{\prime} .37^{\prime \prime} \mathrm{W}\right)$ from allopatric Sicilian populations were collected in June 2009 by allowing females to oviposit on wet filter paper after capture. Resulting clutches were transported to the laboratory and maintained until larvae hatched (for details of the larval rearing methodology, see Sánchez-Guillén, Van Gossum \& Cordero-Rivera, 2005; Van Gossum, Sánchez-Guillén \& Cordero-Rivera, 2003), resulting in approximately 100 adults for each of the three species. Note that mortality at the last instar is almost zero, whereas mortality from after eggs hatching until the last-instar larvae (under laboratory conditions) is almost 90\% (Van Gossum et al., 2003). Emerging individuals were immediately moved to small glass jars where they were kept for 1 day. Animals were then housed in insectaries $(50 \times 50 \times 50 \mathrm{~cm})$ separated by sex and species.

After females (4-8 days old) and males (4-6 days old) reached sexual maturation, they were used for the different experiments. Each individual was used only once in a mating experiment to ensure that all experimental individuals were virgins, and to prevent mechanical damage, sperm depletion, and pseudoreplication (Sánchez-Guillén et al., 2012). After matings, females were allowed to oviposit up to three clutches. Egg clutches were maintained in small Petri dishes until hatching (which took approximately 15 days). We obtained conspecific crosses of $I$. genei and crosses, in both reciprocal directions, between $I$. genei and I. elegans, and between I. genei and I. graellsii. Data on fecundity and fertility of conspecific crosses of I. elegans and I. graellsii (from the same populations and which were maintained and under the same conditions in the laboratory) were obtained from a previous study (Sánchez-Guillén et al., 2012). Additionally, larvae and adults were reared and maintained under the same conditions in both studies.

Calculation details of the absolute contribution of each barrier, four prezygotic barriers (temporal, sexual, mechanical ${ }_{\mathrm{I}}$, and mechanical ${ }_{\text {II }}$ ) and the three postmating prezygotic barriers (oviposition success, fecundity, and fertility) are summarized in Table 1. Results are provided as the mean $\pm \mathrm{SE}$ unless stated otherwise.

\section{MORPHOLOGICAL ANALYSIS: SECONDARY GENITALIC STRUCTURES AND BODY SIZE}

The anatomical mis-match of the male's anal appendages and female pronotum causes mechanical isolation 
Table 1. Formulae of the index of reproductive isolation (RI) of each isolation barrier: four premating prezygotic barriers (temporal, sexual, mechanical I, and mechanical II) and three postmating prezygotic barriers (oviposition success, fecundity and fertility)

\begin{tabular}{|c|c|c|c|}
\hline Barrier & Isolation measure & Range & Formula \\
\hline \multirow[t]{4}{*}{ Premating } & Temporal & 0 to 1 & $\begin{array}{l}\mathrm{RI}_{\text {temporal }}=1-(\text { conspecific matings of both species overlapping during } \\
\text { the day }) /(\text { total observed matings })\end{array}$ \\
\hline & Sexual & -1 to 1 & $\begin{array}{l}\mathrm{RI}_{\text {sexual }}=1-(\text { observed heterospecific tandem attempts }) / \text { heterospecific } \\
\text { tandem attempts expected under random mating) }\end{array}$ \\
\hline & Mechanical $_{\text {I }}$ & 0 to 1 & $\mathrm{RI}_{\text {mechanical } \mathrm{I}}=1-($ tandems/attempts tandem $)$ \\
\hline & Mechanical & 0 to 1 & $\mathrm{RI}_{\text {mechanical } \mathrm{II}}=1-($ matings $/$ tandems $)$ \\
\hline \multirow[t]{3}{*}{$\begin{array}{l}\text { Postmating, } \\
\text { prezygotic }\end{array}$} & Oviposition & -1 to 1 & $\begin{array}{l}\mathrm{RI} \text { oviposition }=1-(\% \text { females oviposited heterospecific matings } / \% \text { females } \\
\text { oviposited conspecific matings })\end{array}$ \\
\hline & Fecundity & -1 to 1 & $\begin{array}{l}\mathrm{RI}_{\text {fecundity }}=1-(\text { mean fecundity heterospecific matings/mean fecundity } \\
\text { conspecific matings })\end{array}$ \\
\hline & Fertility & -1 to 1 & $\begin{array}{l}\mathrm{RI} \text { fertility }=1-(\text { mean fertility heterospecific matings/mean fertility } \\
\text { conspecific matings })\end{array}$ \\
\hline
\end{tabular}

in ischnurans damselflies (Sánchez-Guillén et al., 2012) and in many related damselflies (Paulson, 1974; Robertson \& Paterson, 1982; McPeek et al., 2008; McPeek, Shen \& Farid, 2009). This is because copulation is achieved when males grasp females by their pronotum (tandem position), using their anal appendages and, subsequently, females blend their abdomen to bring the genitalia into contact (wheel position). Differences in anal appendages have been reported between the three sister species. For this reason, the posterior male anal appendages (cerci and paraprocts) and the lateral female pronotum were described for the three species using a binocular microscope and digitized using a camera (Nikon Digital Sight DS-Fi1). Additionally, body lengths of males and females were measured using 278 samples (138 males and 140 females, from different allopatric populations) of the three species to test the prediction proposed by Grant \& Grant (1997) that mechanical isolation can prevent hybridization between the male of the small species with the female of the bigger species. Multiple pairwise comparisons were performed using Dunn's procedure, with a Bonferroni corrected significance level of 0.0167 .

\section{PREMATING PREZYGOTIC BARRIERS}

\section{Experiment 1: temporal isolation}

Ischnura elegans, I. graellsii, and I. genei have similar phenologies across both their sympatric (I. elegans and I. graellsii) and allopatric (I. elegans, I. graellsii, and I. genei) areas of distribution (Dijkstra \& Lewington, 2006). However, because we investigated the strength of reproductive barriers between allopatric populations in the present study, it was not possible to estimate the seasonal components of temporal isolation in the wild. Instead, we measured the timing of reproductive activity of all study species in the laboratory under a common setting. To estimate the amount of temporal isolation, we compared the time during the day at which conspecific copulations take place (only using males and females that were fully sexually mature, which occurred when adults were 4-6 or 4-8 days old, depending on the species). For this experiment, every day, we placed all mature males and all conspecific mature females in the focal insectary. Observations lasted from 07.00-19.00 h (clock time) and included conspecific copulations of I. genei $(N=11)$, which started at $07.47 \mathrm{~h}$ and finished at $14.02 \mathrm{~h}$. We used data of conspecific $I$. graellsii $(N=38)$ copulations, which started at $11.03 \mathrm{~h}$ and finished at $17.15 \mathrm{~h}$, and data of I. elegans $(N=17)$ copulations, which started at $13.31 \mathrm{~h}$ and finished at $17.37 \mathrm{~h}$ copulations from Sánchez-Guillén et al. (2012).

\section{Experiment 2: sexual isolation}

Sexual isolation was estimated as a male's attempt to mate (grasp females by their pronotum) with a conspecific versus heterospecific female. For this, we placed 10 males and five conspecific and five heterospecific females in the same insectary. The following species combinations were used: (1) I. elegans males, I. elegans females, and I. genei females; (2) I. genei males, I. genei females, and I. elegans females; (3) I. graellsii males, I. graellsii females, and I. genei females; and (4) I. genei males, I. genei females, and I. graellsii females. Observed and expected (under random mating) tandem attempts were compared using chi-squared tests (Table 2).

\section{Experiment 3: mechanical isolation}

Mechanical isolation was estimated by measuring incompatibility between the male cerci and female 


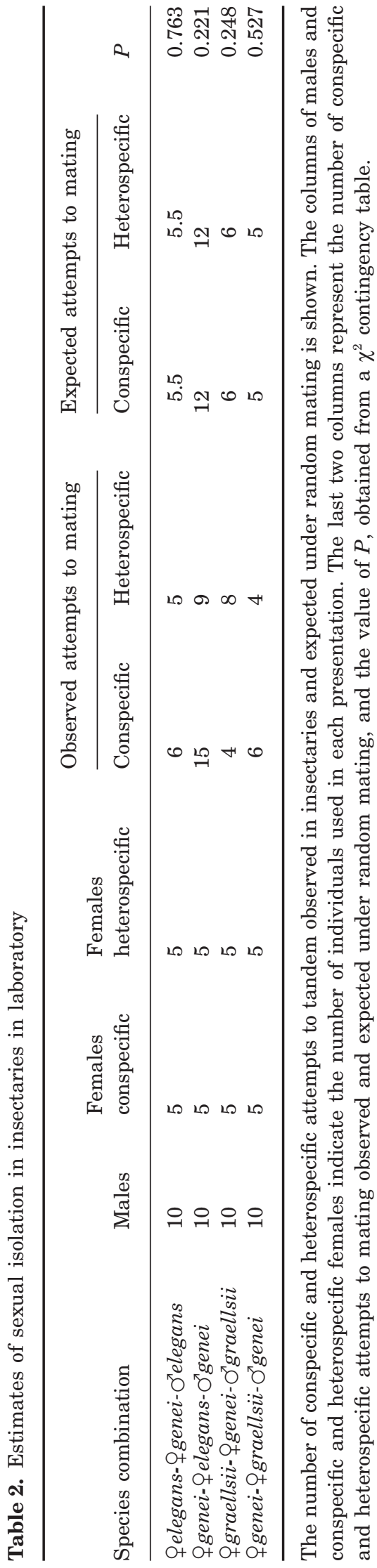

prothorax (mechanical isolation ${ }_{1}$, males attempt to grasp females but fail to engage them) and the incompatibility between male-female genitalia (mechanical isolation II, both genitalia come into contact but fail to engage) in heterospecific versus conspecific crosses (Table 3). For this experiment, we placed males of I. elegans with females of I. genei, males of I. genei with females of I. elegans, males of I. graellsii with females of I. genei, males of I. genei with females of I. graellsii, and males of I. genei with females of I. genei in the same insectary and, for each species and sex combination, we estimated the proportion of males that failed when attempting to form the tandem, as well as the proportion of males that failed when attempting copulation (genitalic contact).

\section{POSTMATING PREZYGOTIC BARRIERS}

During copulation, females receive stimulus-based information of aberrant morphology and inappropriate movements that affects the reproductive output of females even after successful copulation. This can occur, for example, when females prematurely interrupt copulation, expel sperm (Coyne \& Orr, 2004) or avoid oviposition (Sánchez-Guillén et al., 2012).

\section{Experiment 4: gametic isolation}

Oviposition success, fecundity, and fertility were measured in all heterospecific crosses between $I$. elegans $\times I$. genei and I. graellsii $\times I$. genei and conspecific crosses of $I$. genei that achieved copulation (for samples sizes, see Table 3). Oviposition, fecundity and fertility data for conspecific crosses between I. elegans and I. graellsii were obtained from a previous study (Sánchez-Guillén et al., 2012). Reduction in oviposition success was estimated by comparing the percentage of females mated by a conspecific male that oviposited versus the percentage of females mated by a heterospecific male that oviposited. Isolation by a reduction in the fecundity of females (measured as the number of eggs in the first three clutches) and by a reduction of fertility (proportion of fertile eggs) were compared between conspecific and heterospecific pairs. We considered all eggs as fertile if they hatched or showed a developing embryo, aiming to minimize biases as a result of laboratory conditions (Sánchez-Guillén et al., 2012).

\section{TOTAL REPRODUCTIVE ISOLATION}

Cumulative reproductive isolation for each species combination was estimated using Eqns 1-6 in Ramsey, Bradshaw \& Schemske (2003). The effect of reproductive barriers that act later in the mating cycle is reduced by the strength of earlier barriers. In our case, the chronological order is: temporal, sexual, 


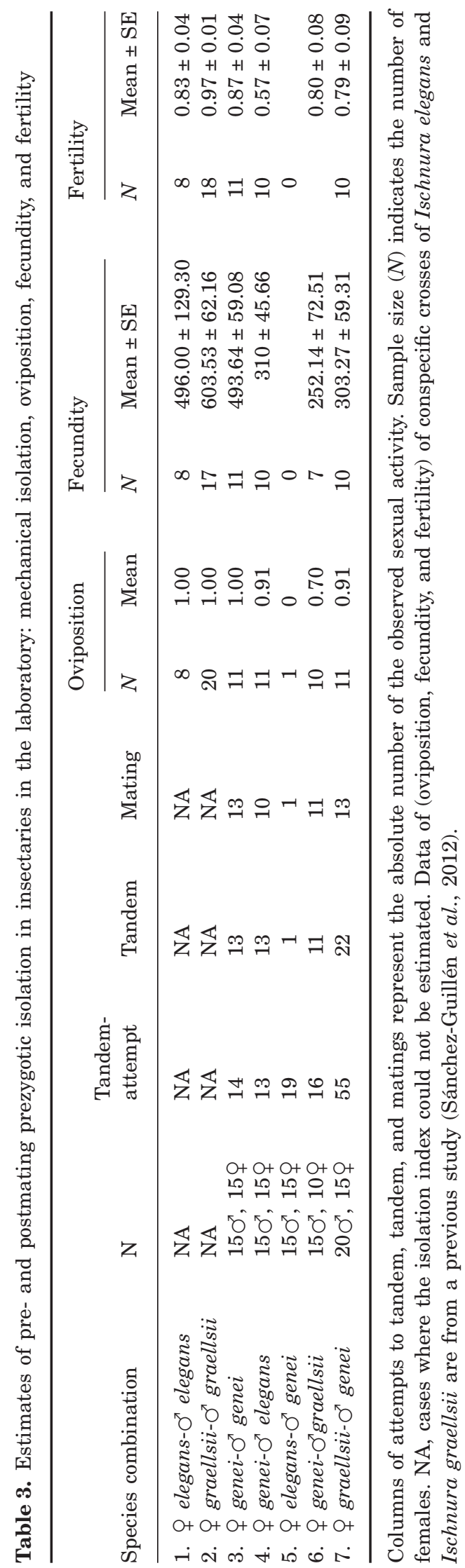

mechanical isolation, oviposition success, fecundity, and fertility. The relative contribution of each reproductive barrier is estimated as the ratio of its absolute contribution to the total strength of reproductive isolation. Total reproductive isolation was calculated as the sum of all relative contributions. Calculation details of the absolute contribution of each barrier of reproductive isolation are summarized in Table 1.

\section{RESULTS \\ MORPHOLOGICAL ANALYSIS}

Males and females of different species differed in body size (males: Kruskal-Wallis test $=73.49, P<0.0001$; females: Kruskal-Wallis test $=74.034, P<0.0001$ ). The body size of I. elegans males $(30.39 \pm 0.23 \mathrm{~mm})$ was the largest of all males. Similarly, females I. elegans were larger $(31.06 \pm 0.22 \mathrm{~mm})$ than females of I. graellsii and I. genei (Fig. 2). However, body size distributions of I. graellsii and I. genei males and females were similar (males ranged from 26.80 to $27.01 \mathrm{~mm}$ and females from 27.01 to $27.34 \mathrm{~mm}$, respectively) (Fig. 2). Visual microscope investigations of female pronotum and male secondary genitalia (i.e. male anal appendages; cerci and paraprocts) revealed that I. elegans can also be separated from the other two species through the upright projection of the pronotum hind border, and through the overall larger size of the pronotum, compared to the other species (Fig. 2), and further in males because of the parallel anal cerci and long paraprocts (Fig. 2). Anal cerci are morphologically different between the species; namely, in I. graellsii, the cerci are parallel but, in I. genei, they cross over. In both species, paraprocts are shorter compared to I. elegans. In addition, in these two species, the pronotum is also shorter than in I. elegans (Fig. 2).

\section{PREMATING PREZYGOTIC BARRIERS}

In both species, combinations of $I$. genei $\times$ I. elegans and $I$. genei $\times I$. graellsii, we detected significant temporal and mechanical isolation, whereas sexual isolation was not detected (i.e. matings were random with respect to species status).

In the first species combination, between I. genei and I. elegans, temporal isolation impeded $50 \%$ of the heterospecific interactions (i.e. only 25 out of the 50 observed conspecific matings of I. elegans and of I. genei overlapped temporally). Between I. genei females and I. elegans males, we detected random mating (i.e. the observed and expected attempts to tandem were similar) (Table 2). Furthermore, although mechanical isolation did not impede tandem formation, it did impede $23.07 \%$ of copulations (Table 3). Matings between I. elegans females and 


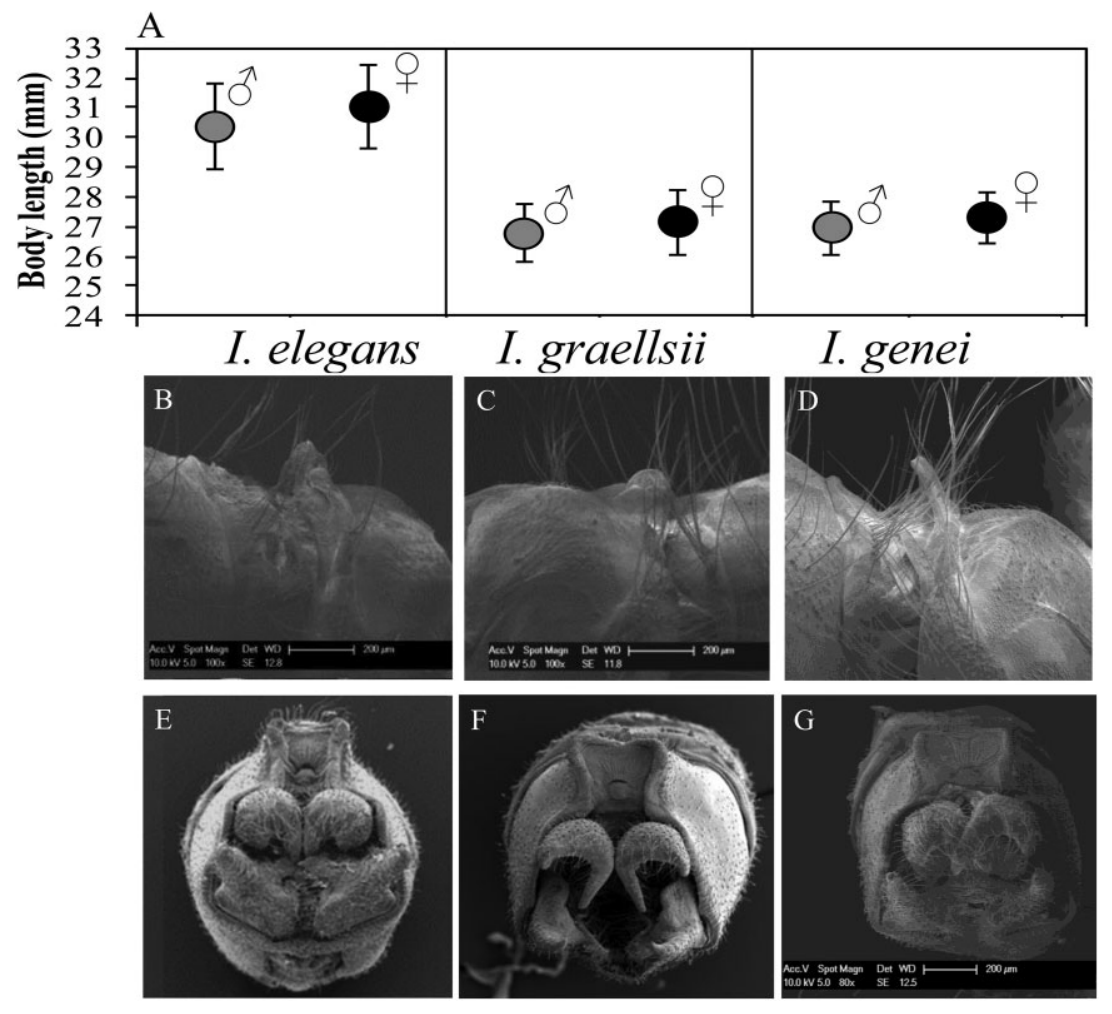

Figure 2. Body length (A). Anterior view of the pronotum of the female (B-D) and male abdominal appendages in anal view (E, F, G) for the three sister species (Ischnura elegans, Ischnura graellsii, and Ischnura genei), respectively.

I. genei males were also random (Table 2). However, although mechanical isolation impeded in $95 \%$ of tandems in this cross direction, some resulted in copulation (one copulation of a total of 19 tandem attempts) (Table 3).

In the second species combination, between I. genei and I. graellsii, temporal isolation prevented a high proportion of putative heterospecific matings between I. genei and I. graellsii because only 30\% (eight of the 27) of conspecific matings overlapped temporally. Between I. genei females and I. graellsii males, there was no sexual isolation (Table 2) and, although mechanical isolation impeded $31 \%$ of tandems, it had no effect on the copulation probability (Table 3 ). Between I. graellsii females and I. genei males, matings were also random (Table 2) and mechanical isolation prevented $60 \%$ of tandems and $41 \%$ of copulations (Table 3).

\section{PostMATING PREZYGOTIC BARRIERS}

In heterospecific crosses of $I$. genei $\times$ I. elegans and $I$. genei $\times I$. graellsii, we were able to quantify partial isolation in all three postmating barriers. Ninety-one percent ( $N=11$ females) of $I$. genei females that mated with $I$. elegans males oviposited eggs but females were less fecund $(310 \pm 45.66 ; U=23.0, P=0.024$, Mann-
Whitney $U$-test) and eggs less fertile [57\%; generalized linear model (GLM) with binomial errors and logit link, deviance ratio $=21.32, P<0.001]$ compared to conspecific combinations (fecundity: $493.6 \pm 59.08$; fertility: $87 \%$ ) (Table 3 ). In the only mating obtained between $I$. elegans females $\times I$. genei males, the female did not oviposit (Table 3).

Seventy percent ( $N=10$ females) of $I$. genei females that mated with I. graellsii males oviposited but females were again less fecund $(252 \pm 72.5 ; U=14.0$, $P=0.027$, Mann-Whitney $U$-test), although they had similar fertility (80\%; GLM with binomial errors and logit link, deviance ratio $=0.03, P=0.866$ ) relative to conspecific combinations (fecundity: $493 \pm 59.08$; fertility: 87\%) (Table 3). When I. graellsii females mated with $I$. genei males, $91 \%(N=11$ females $)$ of the females oviposited. These females again were less fecund $(303 \pm 59.31 ; U=31.0, P=0.002$, MannWhitney $U$-test) and less fertile (79\%; GLM with binomial errors and logit link, deviance ratio $=16.49$, $P<0.001$ ) relative to conspecific crosses (fecundity: $603.05 \pm 62.16$; fertility: 97\%) (Table 3).

\section{TOTAL REPRODUCTIVE ISOLATION}

Temporal isolation between crosses was important and prevented between $50-70 \%$ of possible interactions 

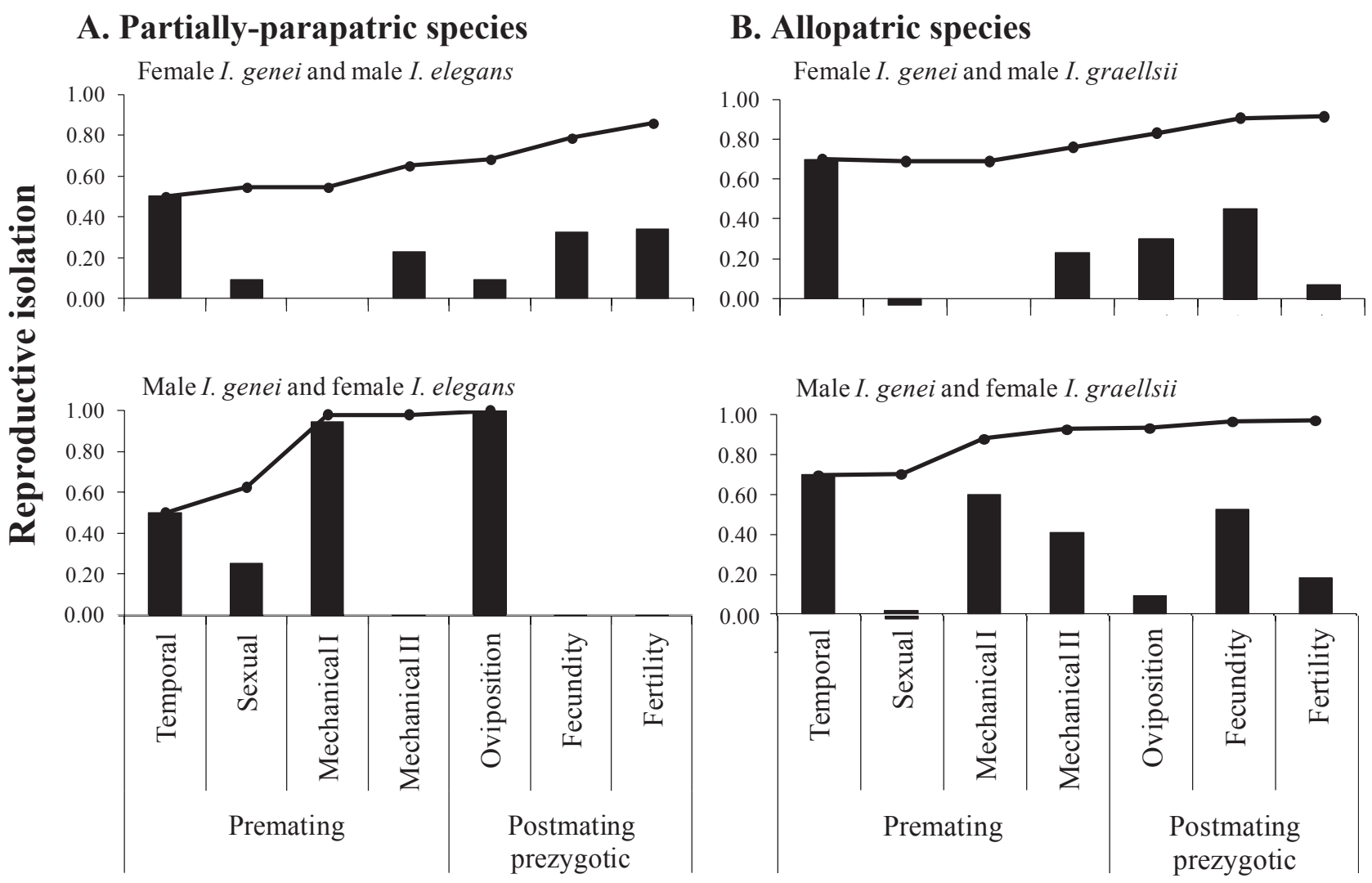

Figure 3. Total reproductive isolation. Absolute contribution (represented by bars) and relative accumulated contribution (represented by lines) of each reproductive barrier to total reproductive isolation between Ischnura genei $\times$ Ischnura elegans (A) and Ischnura genei $\times$ Ischnura graellsii (B).

between pairs. Likewise, mechanical isolation was also a strong barrier between crosses and acted highly asymmetrically between crosses: I. elegans females $\times$ I. genei males (98\%) (Fig. 3A), I. genei females $\times I$. elegans males (65\%) (Fig. 3A); I. graellsii females $\times$ I. genei males (76\%) (Fig. 3B), and I. genei females $\times I$. graellsii males (31\%) (Fig. 3B). No evidence was found for sexual isolation.

Postmating prezygotic barriers were generally less strong and asymmetric (Fig. 3). Between I. genei females and I. elegans males, postmating isolation reduced $21 \%$ of zygote formations but, between $I$. elegans females and I. genei males, the reduction was only $2 \%$ (Fig. 3A). Between I. genei females and $I$. graellsii males, the reduction in zygote formation was $12 \%$, whereas zygotes between $I$. graellsii females and I. genei males were prevented in $3 \%$ of cases (Fig. 3B).

Total prezygotic (premating and postmating) isolation between I. genei females and I. elegans males was 86\% (Fig. 3A) and much lower than between I. elegans females and I. genei males, which was complete (Fig. 3A). Between I. genei females and I. graellsii males, total prezygotic was also high (93\%) (Fig. 3B) and similar to the total prezygotic isolation index obtained for I. graellsii females and I. genei males (99\%) (Fig. 3B).

\section{DISCUSSION}

The present study investigated reproductive barriers in two Ischnura species combinations (I. genei $\times I$. elegans and $I$. genei $\times I$. graellsii) that are sister species, by quantifying the strength of isolating barriers using experimental approaches in the laboratory. Ischnura genei and I. elegans are mainly allopatric, although they occur sympatrically over a small part of their geographical distribution and, where this occurs, the species show extensive introgression (Sánchez-Guillén et al., 2014). Ischnura genei and I. graellsii are allopatric across their range. In the laboratory, both species combinations can easily hybridize, suggesting that geographical isolation is fundamental to species persistence in the latter pair. Overall, the present study shows that premating barriers in the studied species are generally strong and contribute disproportionally to reproductive isolation, which is consistent with previous findings on barriers between I. elegans and 
I. graellsii. We also found that multiple barriers are at work in all species combinations, and that some barriers are highly asymmetric. Below, we discuss premating and postmating barriers in turn and assess their importance in species maintenance, and, lastly, speculate what the strength of barriers can tell us about possible speciation routes in this group.

\section{PREMATING PREZYGOTIC BARRIERS}

We did not detect signs of sexual barriers between the study species, which is consistent with previous studies investigating I. elegans and I. graellsii (Sánchez-Guillén et al., 2012), as well as several nonterritorial damselfly genera without courtship, such as Lestes and Enallagma (Turgeon et al., 2005). Future work should aim to increase the sample sizes of experiments investigating sexual premating barriers in odonates and test whether sexual isolation is indeed absent in this group. Ischnuran species show no precopulatory courtship, which raises the question of how males recognize females. Males and at least one of the several female morphs have colourful (predominantly, green and blue patterns) body patches, and stripes, whereas there is consistently one pale-like female morph (Van Gossum et al., 2008). We are unaware of any work in our study species in relation to the use of such body colour variation in mate discrimination. However, a recent study in Ischnura heterosticta indicates that males are able to find and discriminate female morphs on the basis of female body colour (Huang et al., 2013). This result may apply to other ischnuran species (including those we used in the present study) given their relatively uniform body colour pattern and sexual biology. Males of I. elegans show an innate preference for the male-mimicking androchrome female colour morph (for colour morph descriptions, see Sánchez-Guillén et al., 2005) but undergo ontogenetic changes in male mate preferences towards a preference for gynochrome, likely as a result of learned mate recognition (Sánchez-Guillén et al., 2013b). This is in contrast to studies performed in other groups where sexual isolation can be fundamental in starting divergence between lineages (Coyne \& Orr, 2004) and the rapid diversification of species groups (Price, 1998; Gray \& Cade, 2000; Boake, 2005; Mendelson \& Shaw, 2005), especially in damselfly species with strong sexual selection (for theoretical treatment, see McPeek \& Gavrilets, 2006; Wellenreuther, Vercken \& Svensson, 2010). Our study indicates that sexual isolation is less important in odonate species lacking courtship and elaborated secondary sexual traits (Cordero, 1989), which contrasts strongly with work on territorial damselflies with courtship, such as species in the genus Calopteryx (Córdoba-Aguilar \& Cordero Rivera, 2005).
By contrast to sexual isolation, we found evidence that temporal isolation does minimize the window of reproductive overlap between species (reproductive activity overlapped $30-50 \%$ ), which is consistent with previous studies in I. elegans and I. graellsii (Sánchez-Guillén et al., 2012) and many studies showing that this barrier is indeed an important isolating mechanism in insects (Hölldobler, 1976). However, there is little evidence of significant temporal isolation in other taxa, except for corals and some algal species (Coyne \& Orr, 2004). Analyses of mechanical isolation showed that this barrier is pervasive in all species combinations and, overall, the strongest barrier preventing reproduction. Premating structural isolation, presumably caused by a mis-match between the male anal appendages and mesostigmal plates of the female pronotum (mechanical isolation I), was important in males with short anal appendages and females with large pronotum (60-95\%). This situation occurs, for example, when I. genei males mate with I. elegans and I. graellsii females. Our results are consistent with previous studies in I. elegans and I. graellsii (Sánchez-Guillén etal., 2012), as well as Enallagma and Argia (Paulson, 1974; Robertson \& Paterson, 1982), in which matings were also impeded between males with short anal appendages and females with a large pronotum. However, by contrast to the prediction of Grant \& Grant (1997) (working with birds) suggesting that mechanical isolation can prevent hybridization between the male of the small species with females of the bigger species, differences in body size alone could not explain mechanical isolation. Although there was no mechanical isolation between the largest male (I. elegans) and the shortest females (I. graellsii and I. genei), mechanical isolation was almost complete between short males (I. graellsii and I. genei) and large females (I. elegans). The asymmetry in mechanical isolation in reciprocal crosses of I. graellsii and I. genei could not be explained by differences in body size because both species have similar body sizes (Fig. 2a). In damselflies that lack pre-copulatory courtship, body size and intromittent genital size does not scale allometrically (Nava-Bolaños et al., 2014). Consistent with this, we detected that incompatibility between primary male and female genitalia (mechanical isolation II) impeded $0 \%$ to $40 \%$ of copulations, independently of the body size. Taken together, these mechanical premating barriers decrease copulation success in the different species combinations to a significant degree (range: $23-95 \%$ ).

Current theory predicts that, in species with strong sexual selection, sexual conflict may act on male traits and female preferences to drive the evolution of pre- and postmating prezygotic barriers through mechanical isolation (both structural and tactile) 
(Coyne \& Orr, 2004). For example, in Diplopoda, divergence in genital shape appears to contribute to reproductive isolation among isolated populations (Wojcieszek \& Simmons, 2013). As a result of mechanical incompatibilities, gene flow between species can either be impeded before mating, by the incompatibility between morphological features, or after mating because of aberrant morphology or inappropriate movements, prompting the female to prematurely interrupt copulation or to expel sperm (Coyne \& Orr, 2004). Studies in beetles (Eberhard, 2002), butterflies (Lorkovic, 1958), damselflies (Paulson, 1974; Robertson \& Paterson, 1982), fruit flies (Coyne \& Orr, 2004), and plants (Niklas, 1982) support the central role of mechanical isolation in reproductive isolation. In damselflies, for example, the rapid development of mechanical isolation through the divergence of anal appendages is common in genera such as Ischnura, Enallagma, and Argia (Paulson, 1974; Robertson \& Paterson, 1982; McPeek et al., 2008; Sánchez-Guillén et al., 2012) and it has been suggested that the driving process of this divergence are antagonistic mating interactions and sexual conflict (Cordero-Rivera \& Córdoba-Aguilar, 2010), as well as divergent ecological selection (McPeek et al., 2008).

\section{POSTMATING PREZYGOTIC BARRIERS}

Postmating isolation, likely caused by species-specific differences in mating interactions and cues (e.g. tactile interactions during copulation), reduced the reproductive output of females between $9 \%$ and $100 \%$, which is similar to heterospecific crosses between I. graellsii and I. elegans (Sánchez-Guillén et al., 2012). A proportion of $9 \%$ and $30 \%$ of I. genei females mated with $I$. elegans and $I$. graellsii males, respectively, did not lay eggs. Additionally, 9\% of I. graellsii females and $100 \%$ (only one female) of I. elegans females did not lay eggs when mated with I. genei males. Given the scramble competition nature of these species, as well as fitness costs associated with excessive matings in damselflies (Cordero, Santolamazza Carbone \& Utzeri, 1998), females may show a general tendency to avoid matings (Gosden \& Svensson, 2009). Females can avoid producing hybrids, first by not bending their abdomen to form wheel position (copulation) or by avoiding egg laying after mating. The different body lengths (and thus body weights) of the three species may exert an influence on hybrid production. In particular, when the heterospecific male is smaller in size than the conspecific male, females commonly resist copulations (e.g. by not bending her abdomen), presumably because smaller males would lack the strength to maintain the mating position for sufficient time.
However, when the heterospecific male is larger in size than conspecific males, females do not resist copulations, and the relatively large and heavy males can thus form and maintain mating wheels for long times. In the latter case, females commonly avoid subsequent egg laying. Such a situation might occur in I. genei females that are mated by $I$. graellsii males (which are both of similar size). Here, 23\% of females avoided copulations and $30 \%$ of females did not lay eggs, whereas, in I. graellsii females mating with I. genei males (where the male is of a smaller size), $41 \%$ of females avoided copulations but only $9 \%$ avoided oviposition.

We measured two other postmating prezygotic barriers, namely reduced fecundity and reduced fertility, and detected that 10-52\% of zygotes failed (compared to conspecific crosses). It has been documented that heterospecific sperm can have high fertilization success, even higher than conspecific sperm (Rugman-Jones \& Eady, 2007). We did not find evidence for this and this is corroborated by heterospecific sperm precedence appearing to be absent in female I. graellsii that had mated with I. elegans males (Sánchez-Guillén et al., 2013a). Finally, studies comparing the overall asymmetry of pre- versus postmating barriers have suggested that the overall asymmetry is much stronger between postmating barriers. Lowry et al. (2008), for example, estimated that they can be up to three times higher than premating barriers in a study on flowering plants. The present study, and a previous study on I. elegans and I. graellsii (Sánchez-Guillén et al., 2012), did not support this finding and, if anything, we found that the opposite was true and that the overall asymmetry was more pronounced between premating barriers (Fig. 2).

\section{ConClusions}

The finding that premating barriers prevented most gene flow between the genetically close species I. elegans and I. genei, I. genei and I. graellsii (present study), and I. elegans and I. graellsii (Sánchez-Guillén et al., 2012), suggests that premating barriers have evolved rapidly in this group, and that the morphological divergence of anal appendages and pronotum is a core factor facilitating premating isolation. Our results strongly indicate that premating prezygotic barriers are more asymmetric than postmating prezygotic barriers for preventing hybrid formation, which is consistent with previous studies showing that reproductive isolation is more commonly caused by several barriers acting together. Sexual isolation was not detected, in contrast to other odonate species where sexual selection has been implicated as a key driver of diversification 
(McPeek \& Gavrilets, 2006; Svensson, Karlsson \& Eroukhmanoff, 2007), indicating that environmental driven range expansions and the subsequent geographical overlap of these species could lead to the species breakdown (Sánchez-Guillén et al., 2011, 2013c).

\section{ACKNOWLEDGEMENTS}

We thank two anonymous reviewers for their helpful comments. We thank Jürgen Ott, Jean Pierre Boudot, Elisa Riservato, and Ivette Galicia for their help with samplings. Jesús Ramsés Chavez Ríos provided comments on earlier versions of the manuscript. This research was funded by the Spanish Ministry of Science and Innovation, grants CGL2008-02799, CGL2008-03197-E, and CGL2011-22629, including FEDER funds. RSG is supported by a postdoctoral grant (Alianza 4 Universidades). MW was supported by a Marie-Curie postdoctoral fellowship and a grant from the Swedish Research Council (VR 2012-3996) and by the Linnaeus center CAnMove at Lund University.

\section{REFERENCES}

Arnold JS, Verrel PA, Tilley SG. 1996. The evolution of asymmetry in sexual selection: a model and a test case. Evolution 50: 1024-1033.

Boake CR. 2005. Sexual selection and speciation in Hawaiian Drosophila. Behavioural Genetics 35: 297-303.

Bolnick DI, Turelli M, López-Fernández H, Wainwright PC, Near TJ. 2008. Accelerated mitochondrial evolution and 'Darwin's corollary': asymmetric viability of reciprocal F1 hybrids in centrarchid fishes. Genetics 178: 1037-1048.

Boudot JP, Kalkman VJ, Azpilicueta-Amorín M, Bogdanovic T, Cordero-Rivera A, Degabriele JL, Dommanget L, Ferreira S, Garriós B, Jovic M, Kotarac M, Lopau W, Marinov M, Mihokovic N, Riservato E, Samraoui B, Schneider W. 2009. Odonata of the Mediterranean and North Africa. Libellula Supplement 9: 1-256.

Carchini G, Cobolli M, De Matthaeis E, Utzeri C. 1994. A study on genetic differentiation in the Mediterranean Ischnura Charpentier (Zygoptera: Coenagrionidae). Advances in Odonatology 6: 11-20.

Cordero A. 1989. Reproductive behaviour of Ischnura graellsii (Rambur) (Zygoptera: Coenagrionidae). Odonatologica 18: 237-244.

Cordero A, Santolamazza Carbone S, Utzeri C. 1998. Mating opportunities and mating costs are reduced in androchrome female damselflies, Ischnura elegans (Odonata). Animal Behaviour 55: 185-197.

Cordero-Rivera A. 2000. An analysis of multivariate selection in a non-territorial damselfly (Odonata: Coenagrionidae). Etologia 8: 37-41.
Cordero-Rivera A, Córdoba-Aguilar A. 2010. Selective forces propelling genitalic evolution in Odonata. In: Leonard J, ed. The evolution of primary sexual characters in animals. Oxford: Oxford University Press, 332-352.

Córdoba-Aguilar A, Cordero Rivera A. 2005. Evolution and ecology of Calopterygidae (Zygoptera: Odonata): status of knowledge and future research perspectives. Neotropical Entomology 34: 861-879.

Coyne JA, Orr HA. 1989. Patterns of speciation in Drosophila. Evolution 43: 849-857.

Coyne JA, Orr HA. 2004. Speciation. Sunderland, MA: Sinauer.

Dijkstra KD, Lewington R. 2006. Field guide to the dragonflies of Britain and Europe. Totnes: British Wildlife Publishing Ltd.

Dobzhansky T. 1937. Genetics and the origin of the species. New York City, NY: Columbia University Press.

Dopman EB, Robbins PS, Seaman A. 2010. Components of reproductive isolation between North American pheromone strains of the European corn borer. Evolution 64: 881-902.

Dumont HJ. 2013. Phylogeny of the genus Ischnura with emphasis on the Old World taxa (Zygoptera: Coenagrionidae). Odonatologica 42: 301-308.

Eberhard WG. 2002. Physical restraint or stimulation? The function(s) of the modified front legs of male Archisepsis diversiformis (Diptera, Sepsidae). Journal of Insect Behavior 15: 831-850.

Gosden T, Svensson EI. 2009. Density-dependent male mating harassment, female resistance, and male mimicry. American Naturalist 173: 709-721.

Grant PR, Grant BR. 1997. Mating patterns of Darwin's finch hybrids determined by song and morphology. Biological Journal of Linnean Society 60: 317-343.

Gray DA, Cade WH. 2000. Sexual selection and speciation in field crickets. Proceedings of the National Academy of Sciences of the United States of America 97: 14449-14454.

Haldane JBS. 1922. Sex ratio and unisexual sterility in hybrid animals. Journal of Genetics 12: 101-109.

Hölldobler B. 1976. The behavioral ecology of mating in harvester ants (Hymenoptera: Formicidae: Pogonomyrmex). Behavioral Ecology and Sociobiology 1: 405-423.

Huang SC, Chiou TH, Marshall JL, Reinhard J. 2013. Spectral sensitivities and color signals in a polymorphic damselfly. PLoS ONE 9: e87972.

Kaneshiro KI. 1980. Sexual isolation, speciation, and the direction of the evolution. Evolution 34: 437-444.

Lorkovic Z. 1958. Some peculiarities of spatially and sexually restricted gene exchange in the Erebia tyndarus group. Cold Spring Harbor Symposia on Quantitative Biololgy 23: 319-325.

Lowry DB, Modliszewski JL, Wright KM, Wu CA, Willis JH. 2008. The strength and genetic basis of reproductive isolating barriers in flowering plants. Philosophical Transactions of the Royal Society of London B 363: 3009-3022.

McPeek M, Shen L, Torrey JZ, Farid H. 2008. The tempo and mode of three-dimensional morphological evolution in male reproductive structures. American Naturalist 117: 158-178. 
McPeek MA, Gavrilets S. 2006. The evolution of female mating preferences: differentiation from species with promiscuous males can promote speciation. Evolution 60: 1967-1980.

McPeek MA, Shen L, Farid H. 2009. The correlated evolution of three-dimensional reproductive structures between male and females damselflies. Evolution 63: 73-83.

Mendelson T. 2003. Sexual isolation evolves faster than hybrid inviability in a diverse and sexually dimorphic genus of fish (Percidade: Etheostoma). Evolution 57: 317-327.

Mendelson T, Imhoff VE, Venditi JJ. 2007. The accumulation of reproductive barriers during speciation: postmating barriers in two behaviorally isolated species of darters (Percidae: Etheostoma). Evolution 61: 2596-2606.

Mendelson T, Shaw KL. 2005. Rapid speciation in an arthropod. Nature 433: 375-376.

Monetti L, Sánchez-Guillén RA, Cordero Rivera A. 2002. Hybridization between Ischnura graellsii (Vander Linder) and I. elegans (Rambur) (Odonata: Coenagrionidae): are they different species? Biological Journal of the Linnean Society 76: 225-235.

Nava-Bolaños A, Sánchez-Guillén RA, Munguía-Steyer R, Córdoba Aguilar A. 2014. Isometric damselflies: an examination of male genital allometry in four zygopteran species. Acta Ethologica 17: 47-52.

Niklas KJ. 1982. Simulated and empiric wind pollination patterns of conifer ovulate cones. Proceedings of the National Academy of Sciences of the United States of America 79: 501-514.

Paulson D. 1974. Reproductive isolation in damselflies. Systematic Zoology 23: 40-49.

Polačik M, Reichard M. 2011. Asymmetric reproductive isolation between two sympatric annual killifish with extremely short lifespans. PLoS ONE 6: e22684.

Presgraves D. 2002. Patterns of postzygotic isolation in Lepidoptera. Evolution 56: 1168-1183.

Price T. 1998. Sexual selection and natural selection in bird speciation. Proceedings of the Royal Society of London Series B, Biological Sciences 353: 251-260.

Ramsey J, Bradshaw JR, Schemske DW. 2003. Components of reproductive isolation between the monkey flowers Mimulus lewisii and M. cardinalis (Phrymaceae). Evolution 57: 1520-1534.

Robertson HM, Paterson HEH. 1982. Mate recognition and mechanical isolation in Enallagma damselflies (Odonata: Coenagrionidae). Evolution 36: 243-250.

Rugman-Jones PF, Eady PE. 2007. Conspecific sperm precedence in Callosobruchus subinnotatus (Coleoptera: Bruchidae): mechanisms and consequences. Proceedings of the Royal Society of London Series B, Biological Sciences 274: 983-988.

Sánchez-Guillén RA, Córdoba Aguilar A, Cordero Rivera A, Wellenreuther M. 2014. Genetic divergence predicts reproductive isolation in damselflies. Journal of Evolutionary Biology 27: 76-87.

Sánchez-Guillén RA, Córdoba-Aguilar A, CorderoRivera A. 2013a. An examination of competitive gametic isolation mechanisms between the damselflies Ischnura graellsii and I. elegans. International Journal of Odonatology 16: $259-267$.

Sánchez-Guillén RA, Hammers M, Hansson B, Van Gossum H, Cordero-Rivera A, Galicia-Mendoza DI, Wellenreuther M. 2013b. Ontogenetic shifts in male mating preference and morph-specific polyandry in a female colour polymorphic insect. BMC Evolutionary Biology 13: 116.

Sánchez-Guillén RA, Muñoz J, Tapia G, Feria-Arroyo TP, Córdoba Aguilar A. 2013c. Climate-induced range shifts and hybridisation in insects. PLOS ONE 8: e80531.

Sánchez-Guillén RA, Van Gossum H, Cordero-Rivera A. 2005. Hybridization and the inheritance of intrasexual polymorphism in two Ischnurid damselflies (Odonata: Coenagrionidae). Biological Journal of the Linnean Society 85: $471-481$.

Sánchez-Guillén RA, Wellenreuther M, Cordero-Rivera A. 2012. Strong asymmetry in the relative strengths of prezygotic and postzygotic barriers between two damselfly sister species. Evolution 66: 690-707.

Sánchez-Guillén RA, Wellenreuther M, Cordero-Rivera A, Hansson B. 2011. Introgression and rapid species turnover in sympatric damselflies. BMC Evolutionary Biology 11: 210.

Shine R, Reed RN, Shetty R, Lemaster M, Mason RT. 2002. Reproductive isolating mechanisms between two sympatric sibling species of sea snakes. Evolution 56: 16551662.

Svensson EI, Karlsson K, Eroukhmanoff F. 2007. Gender differences in species recognition and the evolution of asymmetric sexual isolation. Current Biology 17: 19431947.

Turelli M, Moyle LC. 2007. Asymmetric postmating isolation: Darwin's corollary to Haldane's rule. Genetics 176: 1059-1088.

Turgeon J, Stoks R, Thum RA, Brown JM, McPeek MA. 2005. Quaternary radiations of three damselfly clades across the holarctic. American Naturalist 165: E78-E107.

Van Gossum H, Sánchez-Guillén RA, Cordero-Rivera A. 2003. Observations on rearing damselflies under laboratory conditions. Animal Biology 53: 37-45.

Van Gossum H, Sherratt TN, Cordero-Rivera A, Córdoba-Aguilar A. 2008. The evolution of sex-limited colour polymorphism. In: Cordoba-Aguilar A, ed. Dragonflies \& damselflies. Model organisms for ecological and evolutionary research. Oxford: University Press, 219-229.

Wellenreuther M, Vercken E, Svensson EI. 2010. A role for ecology in male mate discrimination of immigrant females in Calopteryx damselflies? Biological Journal of Linnean Society 100: 506-518.

Wojcieszek JM, Simmons LW. 2013. Divergence in genital morphology may contribute to mechanical reproductive isolation in a millipede. Ecology and Evolution 3: 334-343.

Yukilevich R. 2011. Asymmetrical patterns of speciation uniquely support reinforcement in Drosophila. Evolution 66: $1430-1446$. 